\title{
Adubação verde e alterações nas características químicas de um Cambissolo na região de Ji-Paraná-RO
}

\author{
Elaine Almeida DELARMELINDA, Fernando Antônio Rebouças SAMPAIO², Jairo Rafael Machado DIAS³, \\ Leonardo Barreto TAVELLA ${ }^{4}$, Jussie Solino da SILVA ${ }^{5}$
}

RESUMO

A adubação verde promove benefícios nas características químicas, físicas e biológicas do solo. O trabalho avaliou o efeito da incorporação de diferentes adubos verdes nas características químicas de um Cambissolo háplico eutrófico. Foi utilizado o delineamento em blocos ao acaso, com oito tratamentos e três repetiçóes. Os tratamentos consistiram das seguintes leguminosas: Calopogonium mucunoides, Crotalaria juncea, C. spectabilis, Cajanus cajan, Macrotyloma, Mucuna pruriens, Pueraria phaseoloides e a testemunha (sem leguminosa). As avaliaçóes foram realizadas 60 dias após o corte e incorporação. A utilização de leguminosas como adubação verde proporcionou aumento nos teores de matéria orgânica, soma de bases e percentagem de saturação por bases, destacando-se a Pueraria phaseoloides, C. juncea e C. spectabilis.

PALAVRAS-CHAVE: Adubos verdes, biomassa, características químicas do solo.

\section{Green manure and changes on chemical characteristics of a soil in the Ji- Paraná-RO region}

\section{ABSTRACT}

The green manure promotes benefits on the chemical, physical and biological properties of soil. The experiment evaluated the effect of incorporation of differents green manure on the chemistry characteristics of a soil. Experimental design used was a randomized block, with eight treatments and three replications. Treatments were: Calopogonium mucunoides, Crotalaria juncea, Crotalaria spectabilis, Cajanus cajan, Macrotyloma axillare, Mucuna pruriens and Pueraria phaseoloides and the treatment control (without leguminous)). Evaluations of soil samplings were performed in 60 days after handling were performed. The results showed significant effects of the leguminous crop Pueraria phaseoloides, C. juncea and C. spectabilis on the fertility of the soil, with significant increments of organic matter, exchangeable bases and in the base saturation.

KEYWORDS: Green manure, biomass, chemical characteristics of soil.

\footnotetext{
1 Universidade Luterana do Brasil - ULBRA, E-mail: elaineadell@gmail.com

2 Universidade Luterana do Brasil - ULBRA, E-mail: reboucassampaio@hotmail.com

3 Universidade federal do Acre - UFAC, E-mail: jairorafaelmdias@hotmail.com

${ }^{4}$ Universidade federal do Acre - UFAC, E-mail: leo_tavella@hotmail.com

${ }^{5}$ Universidade federal do Acre - UFAC, E-mail: jussiesolino@hotmail.com
} 
Os efeitos promovidos pela adubação verde nas propriedades químicas do solo são bastante variáveis, dependendo da espécie utilizada, do manejo dado à biomassa, da época de plantio e o corte do adubo verde, do tempo de permanência dos resíduos no solo, das condiçóes locais e a da interação entre esses fatores (Alcântara et al. 2000).

A sucessão de diferentes cultivos contribui para a manutenção do equilíbrio dos nutrientes no solo e para o aumento da sua fertilidade, além de permitir uma melhor utilizaçáo dos insumos agrícolas. A adição regular de resíduos de adubos verdes aos vários solos e ambientes agroecológicos dos trópicos contribui para a conservação do solo e da água, melhorando a estrutura do solo que favorece a aeraçáo e a infiltração de água, permitindo uma maior penetração das raízes (Arf et al. 1999).

Os adubos verdes aportam uma grande variedade de substâncias orgânicas ao solo, como exudatos de raízes, biomassa radicular e foliar, ácidos orgânicos e diversas substâncias elaboradas, como aminoácidos, fitormônios, etc. Toda essa matéria orgânica forma um poderoso ativador biológico do solo, melhorando as condiçôes físicas e a ciclagem dos nutrientes. Um manejo de solo com cobertura verde ou morta conserva melhor a umidade do solo, intensificando a atividade biológica e aumentando a disponibilidade de diversos nutrientes, como o nitrogênio e o potássio, que necessitam de umidade suficiente para estarem disponíveis (Osterroht 2002).

Este estudo teve como objetivo avaliar o efeito da incorporação de diferentes adubos verdes nas características químicas de um Cambissolo Háplico eutrófico.

O trabalho foi conduzido na área experimental do Centro Universitário Luterano de Ji-Paraná (CEULJI/ULBRA), no período de dezembro de 2007 a maio de 2008, no município de Ji-Paraná - RO (10 52' 53” S e 61 58' 13” W), com altitude de $152 \mathrm{~m}$ acima do nível do mar. $\mathrm{O}$ clima na regiáo é quente e úmido do tipo Cwi (Köppen) com temperatura variando de 21 a $34^{\circ} \mathrm{C}$. A precipitação média anual varia de 1.800 a 2.000 mm e umidade relativa do ar média de $85 \%$.

O estudo foi realizado sobre um Cambissolo Háplico eutrófico (EMBRAPA 2006), o qual foi submetido ao preparo inicial de forma convencional com uma aração seguida de uma gradagem, sem uso de calagem e adubação mineral. Após o preparo, foram demarcadas 24 parcelas de $2,0 \mathrm{~m}^{2}$ cada $(2 \mathrm{~m}$ x $1 \mathrm{~m}$ ), constituídas de duas linhas no sentido longitudinal espaçadas de $0,50 \mathrm{~m}$ entre si e realizada a semeadura com 40 sementes por metro linear de Calopogonium mucunoides; 20 sementes por metro linear de Crotalaria juncea; 18 sementes por metro linear de Crotalaria spectabilis e Cajanus cajan cv. Caqui; e oito sementes por metro linear de Macrotyloma axillare (E. Mey) Verdc., Mucuna pruriens e Pueraria phaseoloides (T7). Durante o desenvolvimento das espécies foram realizadas capinas manuais para o controle das plantas invasoras em cada parcela.

O delineamento experimental utilizado foi o de blocos ao acaso, com oito tratamentos representados pelas sete espécies de leguminosas em três repetições: Calopogonium mucunoides $\left(\mathrm{T}_{1}\right)$, Crotalaria juncea $\left(\mathrm{T}_{2}\right)$, Crotalaria spectabilis $\left(\mathrm{T}_{3}\right)$, Cajanus cajan cv. Caqui $\left(\mathrm{T}_{4}\right)$, Macrotyloma axillare (E. Mey) Verdc. $\left(\mathrm{T}_{5}\right)$, Mucuna pruriens $\left(\mathrm{T}_{6}\right)$, Pueraria phaseoloides $\left(\mathrm{T}_{7}\right)$ e testemunha ( $\left.\mathrm{T}_{8}\right)$ (área sem cultivo, com vegetação espontânea).

Após 60 dias do plantio, foi realizado o corte das leguminosas com o auxílio de um terçado e a incorporação com auxílio de enxada ao solo à $25 \mathrm{~cm}$ de profundidade. Depois de 60 dias da incorporação dos resíduos orgânicos, foram coletadas amostras de solo na profundidade de $20 \mathrm{~cm}$ em cada parcela experimental e realizadas análises químicas dos solos. Nas amostras coletadas, foi determinado o $\mathrm{pH}$ do solo em $\mathrm{H}_{2} \mathrm{O}$ (acidez ativa), os teores de alumínio (acidez trocável), as bases trocáveis $\left(\mathrm{Ca}^{2+}, \mathrm{Mg}^{2+}\right.$ e $\left.\mathrm{K}^{+}\right)$e a acidez potencial $\left(\mathrm{H}^{+}\right.$ $\left.+\mathrm{Al}^{3+}\right)$, conforme EMBRAPA (1997). Posteriormente, foi determinada a soma de bases (SB), a CTC potencial (T) e a saturação por bases $(\mathrm{V})$.

Os resultados obtidos foram submetidos à análise de variância e quando apresentaram significância, suas médias foram contrastadas pelo teste Tukey ao nível de 5\% de probabilidade.

Para as características SB e V foram encontrados diferenças significativas entre os tratamentos, com a puerária proporcionando os maiores valores no solo (Tabela 1). Azevedo et al. (2007), avaliando as fraçóes lábeis do carbono e nitrogênio do solo, além dos atributos químicos em cultivo de couve consorciada com leguminosas sob manejo orgânico, também encontraram aumentos significativos dessas características no solo estudado. Neste sentido, Luz et al. (2005) ressaltam que em solos tropicais, a CTC da matéria orgânica pode representar grande percentual da CTC total do solo (70-90\%), sendo, portanto, fundamental tanto na retenção como na diminuição da lixiviação de nutrientes. A Crotalária juncea proporcionou os maiores teores de matéria orgânica (M.O) no solo, concordando com Faria et al. (2004), que avaliando o efeito da adubação verde nas características químicas do solo e na produtividade e qualidade da uva, observaram incrementos na M.O nos tratamentos com leguminosas em relação à testemunha (sem leguminosa). Azevedo et al. (2007) observaram que a adubação verde em consórcio com a couve proporcionou grande aporte de carbono e nutrientes ao sistema.

As leguminosas usadas como adubos verdes aumentaram os teores de matéria orgânica, soma de bases e percentagem de saturação por bases. De uma forma geral, a Pueraria phaseoloides foi a que proporcionou os melhores resultados. 
Tabela 1 - Características químicas de um Cambissolo para valores de matéria orgânica (M.0), pH em $\mathrm{H}_{2} \mathrm{O}$, soma de bases (SB), capacidade de troca de cátions (T) e percentagem de saturação por bases (V) sob efeito de diferentes espécies de leguminosas

\begin{tabular}{|c|c|c|c|c|c|}
\hline \multirow{3}{*}{ Tratamentos } & \multicolumn{5}{|c|}{ Características Químicas do Solo } \\
\hline & M.0 & $\mathrm{pH}$ & SB & $T$ & V \\
\hline & \multicolumn{2}{|l|}{ dag. $\mathrm{kg}^{-1}$} & \multicolumn{2}{|c|}{$\ldots \ldots \ldots \ldots \mathrm{cmol}_{\mathrm{d}} \mathrm{dm}^{-3} \ldots \ldots \ldots \ldots$} & $\%$ \\
\hline Calopogonium mucunoides & $3,15 b$ & $6,3 \mathrm{a}$ & $3,10 \mathrm{c}$ & $5,63 \mathrm{c}$ & $55,1 \mathrm{c}$ \\
\hline Crotalaria juncea & $4,83 a$ & $6,0 \mathrm{a}$ & $4,33 \mathrm{~b}$ & $7,06 \mathrm{a}$ & $61,3 \mathrm{~b}$ \\
\hline C. spectabilis & $3,38 b$ & $6,5 \mathrm{a}$ & $4,01 \mathrm{bc}$ & $6,16 b$ & $65,1 \mathrm{a}$ \\
\hline Cajanus cajan & $2,52 \mathrm{c}$ & $6,2 \mathrm{a}$ & $3,73 \mathrm{c}$ & $6,21 \mathrm{~b}$ & $60.1 b$ \\
\hline Macrotyloma axillare & $2,48 \mathrm{c}$ & $6,4 \mathrm{a}$ & $4,48 b$ & $6,60 \mathrm{~b}$ & $67,9 \mathrm{a}$ \\
\hline Mucuna pruriens & $3,08 \mathrm{~b}$ & $6,2 \mathrm{a}$ & $4,42 b$ & $6,95 b$ & $63,6 \mathrm{a}$ \\
\hline Pueraria phaseoloides & $3,02 b$ & $6,4 \mathrm{a}$ & $5,24 \mathrm{a}$ & $7,98 \mathrm{a}$ & $65,7 \mathrm{a}$ \\
\hline Testemunha & $2,09 \mathrm{c}$ & $6,3 \mathrm{a}$ & $4,64 \mathrm{~b}$ & $7,88 \mathrm{a}$ & $58,9 \mathrm{bc}$ \\
\hline C.V. $(\%)$ & 26,8 & 1,94 & 15,00 & 14,52 & 6,83 \\
\hline
\end{tabular}

Médias seguidas pela mesma letra, em cada coluna, não diferem entre si pelo teste de Tukey $(P<0,05)$.

\section{BIBLIOGRAFIA CITADA}

Alcântara, F.A. de; Furtini Neto, A.E.; Paula, M.B de; Mesquita, H.A. de; Muniz, J.A. 2000. Green manuring in the recovery of the fertility of an Oxisol dark red degraded. Pesquisa agropecuária brasileira, 35(2): 277-288. (In Portuguese, with abstract in English).

Arf, O.; Silva, L.S.; Alves, M. C.; Sá, M. E. 1999. Effects on wheat crop rotation with corn and green manure in the presence and absence of nitrogen. Bragantia, (58)2: 323-334. (In Portuguese, with abstract in English).

Azevedo, P.H.S.; Silva, E.E.; Almeida, M.M.T.B.; De-Polli, H.; Guerra, J.G.M. 2007. Labile organic matter in soil cultivation of cabbage intercropped with green manure legumes under organic management. Anais do Congresso Brasileiro de Ciência do Solo, 31: 131. (In Portuguese).

EMPRESA BRASILEIRA DE PESQUISA AGROPECUÁRIA. 1997. Manual of Analytical Methods of Soil. 2.ed. Centro Nacional de Pesquisa de Solos. Rio de Janeiro, 212 pp. (In Portuguese).

EMPRESA BRASILEIRA DE PESQUISA AGROPECUÁRIA. 2006. Brazilian System of Soil Classification. 2.ed. Centro Nacional de Pesquisa de Solos, Rio de Janeiro, 306 pp. (In Portuguese).
Espíndola J.A.A.; Almeida, D.L. de; Guerra J.G.M. 1997. Strategies for the use of leguminous green manure in the production units agroecological. Embrapa Agrobiologia, (42): 4-16. (In Portuguese).

Faria, C.M.B.; Soares, J. M.; Leão, P.C.S. 2004. Green manuring grapevine with legumes in the San Francisco submedium. Revista brasileira de ciência do solo, (28): 641-648. (In Portuguese, with abstract in English).

Luz, P.H. DE C.; Vitti, G.C.; Quintino, T.A.; Oliveira, D.B. 2005. Use of green manure on crop cane sugar. GAPE/USP/ESALQ, São Paulo, 53 pp. (In Portuguese).

Recebido em 15/11/2008

Aceito em 11/11/2009 